To be presented at the ASHRAE 1995 Winter Meeting, Chicago, IL, January 28-February 2, 1995 and to be published in the Proceedings.

\title{
The Design and Evaluation of Integrated Envelope and Lighting Control Strategies for Commercial Buildings
}

\author{
Eleanor S. Lee and Stephen E. Selkowitz \\ Building Technologies Program \\ Energy and Environment Division \\ Lawrence Berkeley Laboratory \\ University of California \\ Berkeley, CA 94720
}

June 1994

This research was funded by the California Institute for Energy Efficiency (CIEE), a research unit of the University of Califomia. Additional related support was provided by the Assistant Secretary for Energy Efficiency and Renewable Energy, Office of Building Technologies, Building Systems and Materials Division of the U.S. Department of Energy under Contract No. DE-AC03-76SF00098. 


\section{DISCLAIMER}

This report was prepared as an account of work sponsored by an agency of the United States Government. Neither the United States Government nor any agency thereof, nor any of their employees, make any warranty, express or implied, or assumes any legal liability or responsibility for the accuracy, completeness, or usefulness of any information, apparatus, product, or process disclosed, or represents that its use would not infringe privately owned rights. Reference herein to any specific commercial product, process, or service by trade name, trademark, manufacturer, or otherwise does not necessarily constitute or imply its endorsement, recommendation, or favoring by the United States Government or any agency thereof. The views and opinions of authors expressed herein do not necessarily state or reflect those of the United States Government or any agency thereof. 


\section{DISCLAIMER}

Portions of this document may be illegible in electronic image products. Images are produced from the best available original document. 


\title{
The Design and Evaluation of Integrated Envelope and Lighting Control Strategies for Commercial Buildings
}

\author{
Eleanor S. Lee and Stephen E. Selkowitz \\ Building Technologies Program \\ Energy and Environment Division \\ Lawrence Berkeley Laboratory \\ Berkeley, CA
}

\begin{abstract}
This study investigates control strategies for coordinating the variable solar-optical properties of a dynamic building envelope system with a daylight controlled electric lighting system to reduce electricity consumption and increase comfort in the perimeter zone of commercial buildings. Control strategy design can be based on either simple, instantaneous measured data, or on complex, predictive algorithms that estimate the energy consumption for a selected operating state of the dynamic envelope and lighting system. The potential benefits of optimizing the operation of a dynamic envelope and lighting system are (1) significant reductions in electrical energy end-uses lighting, and cooling due to solar and lighting heat gains over that achieved by conventional static envelope and lighting systems, (2) significant reductions in peak demand, and (3) increased occupant visual and thermal comfort. The DOE-2 building energy simulation program was used to model two dynamic envelope and lighting systems, an automated venetian blind and an electrochromic glazing system, and their control strategies under a range of building conditions. The energy performance of simple control strategies are compared to the optimum performance of a theoretical envelope and lighting system to determine the maximum potential benefit of using more complex, predictive control algorithms. Results indicate that (1) predictive control algorithms may significantly increase the energy-efficiency of systems with non-optimal solar-optical properties such as the automated venetian blind, and (2) simpler, non-predictive control strategies may suffice for more advanced envelope systems incorporating spectrally selective, narrow-band electrochromic coatings.
\end{abstract}

\section{INTRODUCTION}

Developments in building envelope technologies with variable physical properties have created new energy efficiency opportunities to achieve significant savings in building energy, peak demand, and cost, with enhanced occupant satisfaction. Dynamic building envelope technologies include actively controlled venetian blinds (modulated through the tilt angle of the louver), motorized shades and screens, electrochromic glazings that can be modulated from a clear to colored state, dispersed liquid crystal glazings that switch from a clear to translucent state with an applied voltage, fluidized glazings and frames that act as radiators to provide variable thermal conductance, controlled natural ventilation windows, and photovoltaic building facades (Lampert and Ma 1993). Coupled with electric lighting control systems, dynamic envelope and lighting systems can be actively controlled on a small time step to reduce the largest end-use contributors to commercial building electricity consumption: lighting, and cooling due to lighting and solar gains.

The conventional HVAC concept of dynamic control, introduced in the early 1970 's with the development of lower cost microcomputers (Stoecker and Stoecker 1989), has two objectives: (1) to anticipate upcoming weather or interior load conditions to minimize energy use, and (2) to coordinate the operation of the HVAC components according to continuously varying conditions to maintain thermal comfort (Hartman 1988). The "anticipatory" control strategy is often designed to exploit the thermal mass of the building as a source of free cooling to dampen and shorten the whole building energy and peak demand requirements. Working with the previous day's temperature data, the optimal start-up time, setpoints, and ramping rate to pre-cool the thermal mass of the building, for example, can be determined through simulation and used 
on-line during the operation of a building (Kelly 1988).

The objectives for anticipatory or predictive control of dynamic envelope and lighting systems are different. Instead of using the thermal mass of the building to reduce or delay peak loads over a 24-hour cycle, the operation of the dynamic envelope system can be coordinated with the daylighting control system to reduce envelope and lighting heat gains and to reduce the electric lighting power consumption on a short-term basis (e.g., minute by minute). In cooling-dominated climates, for example, the envelope system can be operated to perform the dual, sometimes conflicting, purpose of admitting daylight to offset electric lighting power requirements and reduce heat gains from lighting, while minimizing solar radiation heat gains. To obtain optimal energy savings in this case, predictive control algorithms are useful for determining how envelope and lighting heat gains will affect actual cooling energy use before the dynamic envelope and lighting device is actuated.

Similar to HVAC dynamic controls, the design and evaluation of these predictive control algorithms are complicated by several factors related to the estimation of cooling energy use. (1) The thermal capacitance of the building introduces a time delay to the building's response to instantaneous heat gains. The total load on the cooling and heating system at any point in time is the sum of the instantaneous heat gains and the absorbed and reradiated heat gains from previous hours. Therefore, the design of the control algorithm must account for this time delay to accurately estimate energy use. (2) Describing and evaluating predictive control algorithms using hourly building energy simulation programs such as DOE-2 (Simulation Research Group 1982) is difficult. DOE-2 separates the estimation of loads from the systems and central plant, making simultaneous analysis of heat gains and HVAC energy use prior to actuating the dynamic envelope and lighting device an involved process. The next upgrade to DOE-2, due to be released in March 1995 as PowerDOE, will combine heat gain and energy use calculations in the same time step. ${ }^{1}$ Alternative mathematical models combining frequency response studies and transient numerical analysis, e.g., Laplace transfer functions, can be used to compare different control systems, but these models focus

\footnotetext{
1 The ability to make iterative heat gain and energy use calculations in the same time step with PowerDOE will be available in 1996-1997. Personal communication with Fred Winkelmann, Lawrence Berkeley Laboratory, June 1994.
}

on specific interactions between the building, the HVAC, and control system (Athienitis et al. 1990). (3) System performance variables such as the part-load characteristics of the cooling plant and air-handling system, time delays introduced by air-transport from the HVAC system to the space, and various sensor time constants that alter the control system response, can significantly affect the accuracy of building energy control. (4) Building energy simulation models used with the installed energy management control system (EMCS) are typically based on steadystate conditions. Discontinuities due to large and unanticipated changes in building use, weather, and occupancy can lead to inaccurate control and unrealized energy savings. To maintain the accuracy of the control system in response to changes in the building operating or occupancy conditions, regression-based methods or artificial neural networks applied during the operation of the building can be used to provide feedback or closed-loop control (Kreider and Wang 1991).

In view of these factors, it may be prudent to consider the use of simpler control strategies based on instantaneous, measured data as a precursor to the use of predictive control algorithms. Simple control strategies can be implemented by local, office-by-office control of the dynamic envelope and lighting system, within a self-contained unit at relatively low cost. Instantaneous measurements of transmitted or incident solar radiation, workplane illuminance, or supply and return air temperature can be used as a basis for control. Implementation of predictive control algorithms requires digital controllers and powerful microprocessors. A centralized building energy management control system and an easily reconfigurable open-protocol network will be required to link the various envelope, lighting, and HVAC components. This global building system can also be connected to other building control functions, such as security, fire and life safety, or be tied to utility real-time pricing data and energy end-use diagnostics/monitoring.

In terms of energy performance evaluation, prior research in dynamic envelope and lighting controls has concentrated on simple control strategies. Warner et al. (1992) evaluated the annual energy performance of electrochromic systems which were controlled to modulate visible transmittance on an hourly basis to meet the design workplane illuminance level. Rheault and Bilgen (1987) developed a numerical model to minimize energy requirements, by modulating the louver angle of an automated venetian blind to optimize the floating room temperature within comfort zone limits for a single summer and winter day. 
Papamichael et al. (1986) measured electric lighting savings in a reduced scale model under outdoor conditions for a venetian blind system, controlled to block direct sun, and to permit view or maximize workplane illuminance. Inoue et al. (1988) developed automated venetian blind control strategies based on transmitted direct solar radiation by correlating data gathered from time-lapse photographs.

In this study, the primary objective is to determine the maximum potential energy savings of using more complex, predictive control algorithms over simple control strategies based on instantaneous, measured data. Using the DOE-2 building energy simulation program to model two dynamic envelope and lighting systems, an automated venetian blind and an electrochromic glazing system, this study also identifies the primary envelope design parameters that affect the magnitude of energy savings in perimeter zones of commercial buildings in cooling-dominated climates.

\section{METHOD}

A predictive energy control algorithm for a hypothetical dynamic envelope and lighting system is given in Figure 1 for an instantaneous cooling condition, to illustrate the relationship of cooling and lighting electricity consumption to the solar-optical properties of the dynamic envelope system: visible transmittance (Tv), shading coefficient (SC), and U-value. ${ }^{2}$ The hypothetical system can modulate its solar-optical properties within the full range of possible Tv $(0.0-1.0)$ and $S C(0.0-1.0)$ values. U-value, in this example, is not varied. If the space has continuous daylighting controls, lighting energy will decrease as Tv increases and more daylight is admitted. At some value of $\mathrm{Tv}$, when the daylight level in the space exceeds the design workplane illuminance level, lighting energy use will reach its minimum value where additional increases in $\mathrm{Tv}$ will no longer decrease lighting energy. As lighting energy use decreases, cooling energy due to heat gains from lighting follows a similar relationship. On the other hand, as $\mathrm{SC}$ increases, cooling energy due to solar gains increases throughout the full range of SC. If the dependent relation-

2 The shading coefficient (SC) for the total window system represents the ratio of solar heat gain through the window system relative to that through $3 \mathrm{~mm}(0.125$ in) clear glass at normal incidence. The visible transmittance ( $T v$ ) is defined as the percentage of visible light transmitted through the total window. The U-value is the total heat transfer coefficient of the window system which includes conductive, convective, and radiative heat transfer.

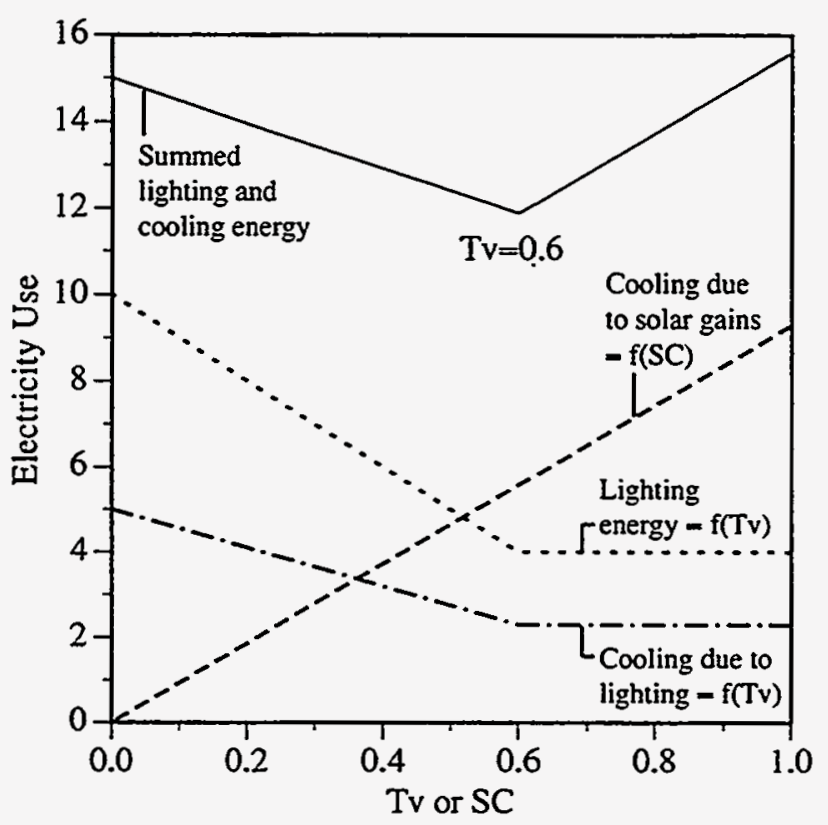

Figure 1. A conceptual diagram of cooling, lighting, and summed electricity use as functions of shading coefficient (SC) or visible transmittance (Tv) for a hypothetical dynamic envelope and lighting system with daylighting controls. The hypothetical system can modulate Tv and SC from 0 to 1.0, where $S C=T v$ in this example. $U$-value is not varied. This relationship is given for an instantaneous cooling condition with an arbitrary scale.

ship of $\mathrm{Tv}$ to $\mathrm{SC}$ is defined, for example $\mathrm{Tv}=\mathrm{SC}$, one can sum the cooling and lighting end uses to obtain total electricity use as a function of Tv. In this example, the choice of $\mathrm{TV}=0.6$ will clearly yield the lowest electricity use. This predictive energy control algorithm therefore involves pre-calculating the lighting and cooling energy balance for all positions or states of the dynamic envelope and lighting system at each time step, then selecting the system position that yields the least energy use.

Since this predictive control algorithm cannot be readily modeled using conventional building energy simulation programs, the energy performance of simple control strategies is characterized using two indices, the solar gain increment and the daylighting increment, which mimic the balance illustrated in the example above (Sullivan et al. 1992). The daylighting increment (DLI) is a measure of the decrease in electricity consumption due to the use of daylighting controls, comprised of the savings in lighting energy use and cooling energy use due to lighting heat gains. 
DLI $=\mathrm{E}_{\mathrm{a} \text {,daylighting }}-\mathrm{E}_{\text {ano daylighting }}$

$=[\mathrm{CE} l t s+\mathrm{LE}+\mathrm{EE}]_{\mathrm{d}}-[\mathrm{CE} l t s+\mathrm{LE}+\mathrm{EE}]_{\mathrm{nd}}$

$=\left[\mathrm{LE}_{\mathrm{d}}-\mathrm{LE}_{\mathrm{nd}}\right]+\left[\mathrm{CE} / t s_{\mathrm{d}}-\mathrm{CE} l t s_{\mathrm{nd}}\right]$

where ${ }_{n d}$ represents no daylighting controls, daylighting controls, $E$ total electricity use, $C E$ lts cooling energy due to electric lighting heat gains, and $L E$ lighting energy for a fixed glazing area, $a$. $E E$ represents all other electricity consumption end uses unaffected by a change between the use of daylighting control and no daylighting controls (e.g., cooling due to solar heat gains, occupant heat gains, equipment electricity use, etc.).

The solar gain increment (SGI) is a measure of the increase in cooling electricity consumption due to solar gains. This is comprised largely of the difference in cooling energy due to solar gains with a small percentage (in cooling-dominated climates) due to the difference between the U-value of the window and an opaque insulated wall.

$$
\begin{aligned}
\mathrm{SGI}= & \mathrm{E}_{\mathrm{a}}-\mathrm{E}_{\mathrm{o}} \\
= & {[\mathrm{CE} s l r+\mathrm{CE} \text { cond }+\mathrm{EE}]_{\mathrm{a}}-} \\
& {[\mathrm{CE} s l r+\mathrm{CE} \text { cond }+\mathrm{EE}]_{\mathrm{o}} } \\
= & {\left[\mathrm{CEs} r_{\mathrm{a}}-\mathrm{CEs} r_{\mathrm{o}}\right]+\left[\mathrm{CE} \text { cond }_{\mathrm{a}}-\mathrm{CE} \text { cond }_{\mathrm{o}}\right] }
\end{aligned}
$$

where ${ }_{a}$ represents an exterior wall with a glazing area of $a$, o represents an exterior wall with an R11 opaque wall, $E$ total electricity use, $C E$ sl $r$ cooling energy due to solar heat gains, $C E$ cond cooling energy due to conductive heat gains through the window or opaque wall, and $L E$ lighting energy with no daylighting controls. $E E$ represents all other electricity consumption end uses unaffected by a change between the use of a window and no window with no daylighting controls (e.g., electric lighting, cooling due to lighting heat gains, occupant heat gains, etc.).

The sum of the daylighting and solar gain increment is the total benefit or liability in electricity use resulting from the use of the dynamic envelope system and daylighting controls or the incremental electricity consumption (IEC).

$\mathrm{IEC}=\mathrm{DLI}+\mathrm{SGI}$

These indices are calculated on a monthly basis to ascertain how the control strategies affect performance under varying weather conditions. Calculating the solar gain and daylighting indices on an hourly basis for peak demand analysis would require significant effort to post process hourly data and was beyond the scope of this study.
The energy performance of the dynamic systems was modeled and evaluated using the DOE-2.1D Building Energy Simulation Program (Simulation Research Group 1989). The DOE-2 program is the building industry standard that requires as input a geometrical description of the building and a physical description of the building construction, HVAC equipment, end use load schedules, utility rates, and hourly weather data to determine the energy consumption of the building. A five-zone prototypical office building module, consisting of ten $10 \mathrm{ft}(3.05$ $\mathrm{m})$ wide by $15 \mathrm{ft}(4.57 \mathrm{~m})$ deep offices in each perimeter zone and a central $10,000 \mathrm{ft}^{2}\left(929 \mathrm{~m}^{2}\right)$ core zone, was modeled in Los Angeles. Perimeter zones were oriented to face the four cardinal directions. Continuous strip windows were modeled in the exterior wall of each perimeter zone. Glazing area was varied from $0 \%$ to $70 \%$ windowto-wall ratio (WWR); where the wall area is defined as the floor-to-floor exterior wall area, and the floor-to-floor height is $12 \mathrm{ft}(3.66 \mathrm{~m})$. A detailed description of the building model is given in Appendix A. The lighting system is summarized in Table 1. A description of the dynamic envelope systems and control strategies is given here.

\section{Electrochromics}

Electrochromic glazings incorporate a multilayer, thin film coating in which a small applied voltage causes ions to migrate from a counter-electrode layer to an

TABLE 1

DOE-2 Electric Lighting System

Lighting Power Density $1.5 \mathrm{~W} / \mathrm{ft}^{2}\left(16.1 \mathrm{~W} / \mathrm{m}^{2}\right)$

Design Workplane Illuminance $50 \mathrm{fc}$ (538 lux)

Continuous Dimming

Electronic Ballasts

Minimum Power Fraction

$10 \%$

Minimum Light Fraction

0.00001

Light Reference Point

$\begin{array}{ll}\text { Height } & 2.5 \mathrm{ft}(0.76 \mathrm{~m}) \\ \text { Width (centerline of space) } & 5 \mathrm{ft}(1.52 \mathrm{~m}) \\ \begin{array}{l}\text { Depth from Window } \\ \quad \text { Electrochromics }\end{array} & 10 \mathrm{ft}(3.05 \mathrm{~m}) \\ \quad \text { Automated Venetian Blind } & 12.86 \mathrm{ft}(3.92 \mathrm{~m})\end{array}$

Fraction of Perimeter Zone

Controlled by Daylighting

Control System

$100 \%$ 
electrochromic layer. This produces a change from a high transmittance clear state to a low transmittance colored state. Solar-optical performance is dependent on the materials used for the electrochromic layer - transition metal oxides or organic materials exhibit different spectral responses and therefore define the range of Tv and SC (Reilly et al. 1991). Two electrochromic glazings were modeled: a hypothetical broad-band electrochromic ( $\mathrm{Tv}=0.09-0.70$, $S C=0.26-0.84$ ) and a hypothetical narrow-band electrochromic $(T v=0.09-0.71, S C=0.11-0.50)$ with a fixed $\mathrm{U}$-value of $0.35 \mathrm{Btu} / \mathrm{h} \cdot \mathrm{ft}^{2} \cdot{ }^{\circ} \mathrm{F}\left(1.99 \mathrm{~W} / \mathrm{m}^{2} \cdot \mathrm{K}\right)$ (Warner et al. 1992). The two electrochromics modulate visible light within nearly the same range, but the narrow-band electrochromic is able to reject most of the near infrared solar radiation so its range of SC is lower than the broadband electrochromic for an equivalent $\mathrm{Tv}$.

The electrochromic control strategy was designed to meet the design workplane illuminance of $50 \mathrm{fc}$ (538 lux) through the modulation of Tv on an hourly basis during daylight hours. In this way, the admission of daylight is limited only to a quantity which will permit maximum displacement of lighting energy use, while imposing a limit on solar gain admission. Direct sun and glare are assumed to be indirectly controlled with this strategy. The workplane illuminance was calculated by DOE- 2 at a reference point $10 \mathrm{ft}(3.05 \mathrm{~m})$ from the window wall, centered on the $10 \mathrm{ft}$ $(3.05 \mathrm{~m})$ wide window wall, and at a workplane height of $2.5 \mathrm{ft}(0.76 \mathrm{~m})$. SC was defined as a linearly dependent variable of Tv between clear and colored states.

\section{Automated Venetian Blind}

Automated venetian blind (AVB) systems provide variable solar-optical control by altering the tilt angle of the louvers. Although venetian blinds are well known and widely available products, they are optically and thermally complex systems due to their curved geometry and semispecular surfaces. The daylighting performance of the automated venetian blind system was therefore characterized using a new method, developed in parallel with this study, that combines measured data with mathematical routines to produce directional workplane illuminance coefficients and daylight factors (Papamichael and Beltrán 1993, see Appendix B). These factors were used in a modified version of the DOE-2 computer program to predict workplane illuminance levels for any combination of sun and sky conditions. For the same reasons, conventional mathematical models of solar gain through glazings cannot be used to determine the thermal performance of the automated venetian blind system. The thermal performance was characterized using a mathematical model derived for a between-pane louver system with diffuse blind surface reflectance (Rheault and Bilgen 1990). The shading coefficient data are given for the full range of blind tilt angles for an average winter and summer solar position (Figure 2). A single value of glazing area, $W W R=0.50$, was used in this analysis, due to the complex and timeconsuming effort required to characterize the optical performance of the automated venetian blind system.

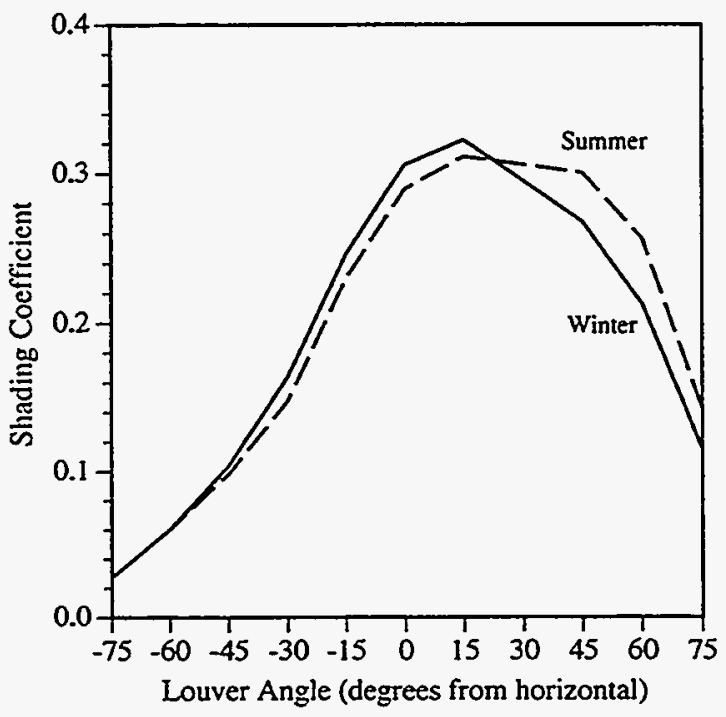

Figure 2. Thermal performance of the automated venetian blind system with a selective low-e glazing for the summer and winter period. The shading coefficient is shown as a function of the venetian blind tilt angle. The thermal performance was mathematically derived for a betweenpane system with gray-diffuse louver surfaces (Rheault and Bilgen 1990). Negative tilt angles permit occupant view of sky, positive angles permit occupant view of the ground.

The automated venetian blind control strategies were designed with an intent similar to the electrochromic strategy: to optimize workplane illuminance. However, the actual implementation of the automated venetian blind control strategy may be more difficult due the system's optical complexity - perhaps requiring a closed-loop feedback control system to ensure proper performance (see companion study, Rubinstein et al. 1993). Therefore, two additional control strategies were explored which may require less sophisticated hardware/software to implement: permit view and maximize workplane illuminance. 
All control strategies were designed to block direct sun to control glare and reduce thermal discomfort due to direct solar radiation:

(1) maximize louver openness (view),

(2) maximize workplane illuminance at RP2 (12.86 ft $(3.92 \mathrm{~m}))^{3}$

(3) optimize workplane illuminance:

(a) maximize RP1 without exceeding design workplane illuminance for RP1 $(6.43 \mathrm{ft}(1.96 \mathrm{~m})$ ),

(b) maximize RP1 without exceeding design workplane illuminance for RP2,

(c) maximize RP2 without exceeding design workplane illuminance for RP1, and

(d) maximize RP2 without exceeding design workplane illuminance for RP2.

The design workplane illuminance of $50 \mathrm{fc}(538 \mathrm{lux})$ was measured at the control strategy reference point depth (RP1 or RP2) from the window wall and at a workplane height of $2.5 \mathrm{ft}(0.76 \mathrm{~m})$. Four variations of control strategy 3 were investigated since the daylight distribution from the automated venetian blind system is more complex than simple glazings: for some tilt angles and sun positions, the distribution may be atypical of sidelit conditions. The venetian blind was operated in the fully down position during all daylight hours. The louvers were operated at discrete $15^{\circ}$ tilt angle increments for a range of $\pm 75^{\circ}$ from the horizontal position. Discrete angles were necessary since each tilt angle required measured data to characterize daylight performance (see Appendix B). For any sun position in the window-facing hemisphere, two critical blind tilt angles that just cut off penetration of direct sun to the space were calculated. Any tilt angles outside the range of these two cut-off angles block direct sun. The discrete $15^{\circ}$ tilt angle that both blocks direct sun and more closely meets the control strategy objective was then selected. From hour to hour, the tilt angle selection was noncontinuous; e.g., hour $1:-15^{\circ}$, hour $2:+75^{\circ}$, etc. Unlike the electrochromics that can be continuously modulated to provide the exact design workplane illuminance, the automated venetian blind system as modeled can only provide workplane illuminance levels that are less than or equal to

3 Note: The difference in the location of the light reference points between the electrochromic and selective low-e glazing systems at $10 \mathrm{ft}(3.05 \mathrm{~m})$, and the automated venetian blind system at $12.86 \mathrm{ft}(3.92 \mathrm{~m})$, are due to the experimental optical measurements taken for the venetian blind system. This modeling difference created an insignificant difference $(<1.34 \%)$ in annual energy use (see Appendix A). the $50 \mathrm{fc}$ ( 538 lux) design workplane illuminance level due to the discrete blind tilt angles. Interpolation of data between the tilt angles is possible, but would require further study due to the complex semi-specular reflectance of the system. Therefore, the daylighting benefit we calculate might be greater if continuous tilt angles were modeled.

\section{Hypothetical Optimum System}

A hypothetical optimum prototype was defined to establish a lower bound of performance. The hypothetical dynamic envelope and lighting system is defined as a system that allows the lighting system to be dimmed to minimum power in all perimeter zones during daylight hours but does not allow any solar gains $(\mathrm{SC}=0)$ to be transmitted through the window.

\section{Conventional Static System}

The performance of a conventional static, spectrally selective low-e insulating glazing system ( $\mathrm{T} v=0.61, \mathrm{SC}=0.41$, $\mathrm{U}$-value $\left.=0.33 \mathrm{Btu} / \mathrm{h} \cdot \mathrm{ft}^{2} \cdot{ }^{\circ} \mathrm{F}\left(1.87 \mathrm{~W} / \mathrm{m}^{2} \cdot \mathrm{K}\right)\right)$ is given with and without the use of an interior diffusing shade to establish an upper bound of performance. The shade is modeled as manually operated where the shade is drawn down completely by the occupant for daylight hours if direct sun or glare is present. The shade is triggered if the transmitted direct solar radiation exceeded $30 \mathrm{Btu} / \mathrm{h} \cdot \mathrm{ft}^{2}$ $\left(94.5 \mathrm{~W} / \mathrm{m}^{2}\right)$ or if the glare index computed using the Hopkinson Cornell-BRS formula exceeds 20 (Simulation Research Group 1989). With the shade drawn, the Tv of the glazing is reduced by $65 \%$ and the SC by $40 \%$. Although the components are "conventional", they are not yet in routine use commercially and the assumed operation and strategy is highly optimistic for a manually controlled shade.

\section{DISCUSSION}

To assess how well simple control strategies are able to achieve the performance of the hypothetical optimum predictive control algorithm, the energy performance indices are first presented for the prototypical office building module with a window-to-wall ratio of 0.50 in Los Angeles. Total annual electricity use and peak demand is summarized in Table 2 (page 10). 


\section{Energy Performance Indices}

For all systems, the solar gain increment (SGI) follows a similar shape throughout the year with diminished magnitude in proportion to the system's effective shading coefficient ${ }^{4}$ (Figure 3a: South and West). For example, compared to the broad-band electrochromic $(\mathrm{SC}=0.26-0.84)$, the narrow-band electrochromic $(\mathrm{SC}=0.11-0.50)$ is able to achieve near optimum solar gain increment performance for all orientations due to its lower SC range. Control strategy design also has a significant effect on the system's performance. Note how the automated venetian blind control strategy designed to provide tighter control of admitted daylight (strategy $3 \mathrm{~d}$ : meet design illuminance levels), rather than maximizing view or workplane illuminance (strategies 1 and 2, respectively), resulted in the least solar gains. For east and south-facing zones, control strategy $3 \mathrm{~d}$ reduces the solar gain increment $30-50 \%$ from month-to-month. For all systems, the solar gain increment approaches near-optimal performance (SGI $\leq 0)$ in the north perimeter zone $(<150 \mathrm{kWh} / \mathrm{mon})$. For all other window orientations, as expected the magnitude of the solar gain increment is more significant $(<800 \mathrm{kWh} / \mathrm{mon})$. Since the solar gain increment is both a measure of cooling energy due to solar heat gains and conductance, a negative SGI value can occur when there is no cooling energy due to solar gains and when the conductance between an insulated wall and the glazing system diminishes the total cooling energy use to less than zero.

As with the solar gain increment, the daylighting increment (DLI) has a similar shape between systems throughout the year with diminished magnitude in proportion to the system's effective visible transmittance (Figure $3 b$ ). For this large selected window area (WWR $=0.50)$ and effective visible transmittance, all systems attain higher than $70 \%$ of the optimum daylighting increment for all orientations throughout the year, indicating daylight saturation within the space. The daylighting increment also maintains the same shape between all orientations in accordance with month-to-month daylight availability, with the maximum reductions occurring during the summer months. Daylighting controls reduce electric lighting requirements,

${ }^{4}$ Since SC is variable for the dynamic envelope systems, the term "effective" is used to describe the equivalent SC of a dynamic system to a conventional static system.

5 Note that the solar gain increment reflects the cooling energy use due to both conductance (U-value) and solar heat gains (SC) over an insulated wall. For some envelope systems in coolingdominated climates, the difference in conductance between an resulting in energy consumption that is less than non-daylit offices, hence, the negative DLI values.

Optimum energy performance is attained when the penalties due to increased solar gains are far exceeded by the daylighting benefits due to decreased lighting energy and decreased cooling due to electric light heat gains. This net effect or balance is represented by the total incremental electricity use: the sum of the solar gain increment and daylighting increment curves (Figure 3c). For example, for the marginal daylighting incremental gains that the automated venetian blind control strategy 1 (maximize view) achieves over strategy $3 d$ (optimize workplane illuminance at $12.86 \mathrm{ft}(3.92 \mathrm{~m})$ ), control strategy 1 suffers significant solar gain incremental losses. The combined incremental electricity consumption of control strategy $3 \mathrm{~d}$ for most months is therefore lower than strategy 1 . Between all systems except the narrow-band electrochromic, the total incremental electricity consumption curves are nearly parallel with small deviations from month to month for all orientations. In the north-facing perimeter zone, all systems achieve more than $70 \%$ of the defined optimum due to high daylighting with little solar heat gains. The narrow-band electrochromic significantly outperforms all other systems, attaining $80-90 \%$ of the optimum performance for all orientations throughout the year. Therefore, using more complex, predictive control algorithms over simple control algorithms would not result in significant energy savings for either the narrow-band electrochromic system or for windows facing north.

If glazing area is varied, the narrow-band electrochromic still yields the highest energy savings between all systems by providing solar gain control with little sacrifice to daylighting benefits (Figure 4). Like all other systems, the narrow-band electrochromic achieves daylight saturation (indicated by the leveling off of the daylighting increment) for WWR $>0.30$. Unlike all other systems, however, the narrow-band electrochromic solargain increment decreases with increases in glazing area simply due to its low SC range. 5 Increasing the performance of the broad-band electrochromic and automated venetian blind systems for $W W R>0.30$ may be accomplished either by improving the

insulated wall and the glazing system diminishes cooling energy use and therefore decreases the solar gain increment. This effect may become a larger percentage of the total solar gain increment, as in the case of the narrow-band electrochromic, and result in a downwards trend in the solar gain increment with increases in glazing area. 

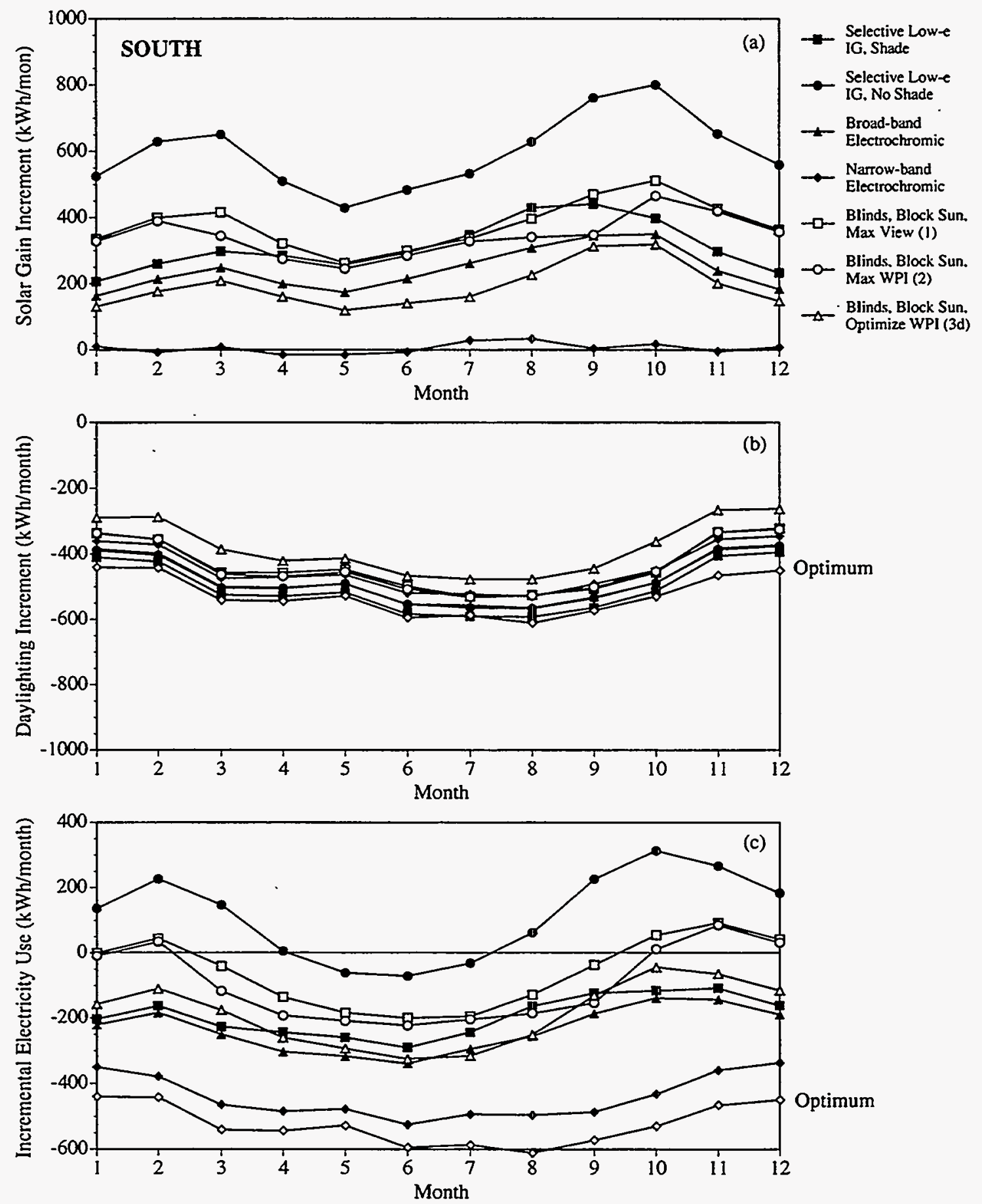

Figure 3 SOUTH ZONE. Incremental electricity consumption for a prototypical commercial office building zone in Los Angeles. The solar gain increment (a) is the incremental energy due to the window over an insulated wall. The daylighting increment $(b)$ is the incremental energy due to daylighting controls. The sum of the solar gain and daylighting increment is the total incremental electricity consumption (c) over an insulated wall. The data show the performance of dynamic systems and a selective low-e glazing system ( $S C=0.41, T v=0.61, U=0.33 \mathrm{Btul} / \mathrm{h} \cdot \mathrm{ft}^{\circ} \mathrm{F}\left(1.87 \mathrm{~W} / \mathrm{m}^{2} \cdot \mathrm{K}\right)$ ) with the use of continuous dimming daylighting controls at a design workplane illuminance (WPI) level of $50 \mathrm{fc}$ (538lux) and a lighting power density of $1.5 \mathrm{~W} / \mathrm{ft}^{2}\left(16.1 \mathrm{~W} / \mathrm{m}^{2}\right)$. The optimum energy performance is shown for a theoretical system that permits no solar gains yet achieves maximum lighting power reduction (10\%) through daylighting throughout the day. The building zone has ten $10 \mathrm{ft}(3.05 \mathrm{~m})$ wide by $15 \mathrm{ft}(4.57 \mathrm{~m})$ deep offices with a window-to-wall ratio of 0.50 . 

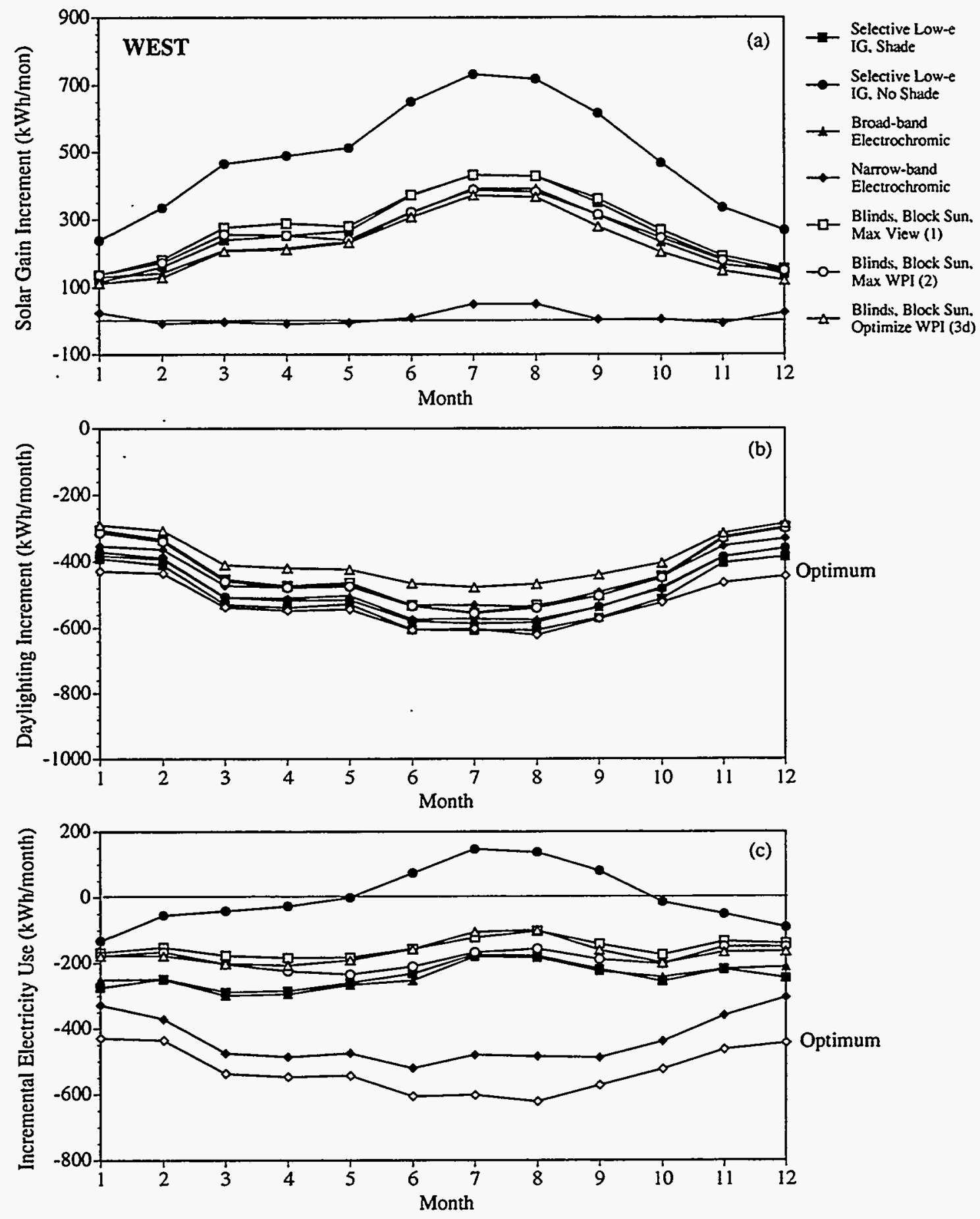

Figure 3 WEST ZONE. Incremental electricity consumption for a prototypical commercial office building zone in Los Angeles. The solar gain increment $(a)$ is the incremental energy due to the window over an insulated wall. The daylighting increment (b) is the incremental energy due to daylighting controls. The sum of the solar gain and daylighting increment is the total incremental electricity consumption (c) over an insulated wall. The data show the performance of dynamic systems and a selective low-e glazing system ( $S C=0.41, T v=0.61, U=0.33 \mathrm{Btul} h \cdot \mathrm{ft}^{2} \mathrm{~F}\left(1.87 \mathrm{~W} / \mathrm{m}^{2} \cdot \mathrm{K}\right)$ ) with the use of continuous dimming daylighting controls at a design workplane illuminance (WPI) level of $50 \mathrm{fc}$ ( 538 lux) and a lighting power density of $1.5 \mathrm{~W} / \mathrm{ft}^{2}\left(16.1 \mathrm{~W} / \mathrm{m}^{2}\right)$. The optimum energy performance is shown for a theoretical system that permits no solar gains yet achieves maximum lighting power reduction (10\%) through daylighting throughout the day. The building zone has ten $10 \mathrm{ft}(3.05 \mathrm{~m})$ wide by $15 \mathrm{ft}(4.57 \mathrm{~m})$ deep offices with a window-to-wall ratio of 0.50 . 
TABLE 2

DOE-2 Annual Electricity Use (kWh) and Peak Demand (W) for Los Angeles

$\begin{array}{rrrrrrr}\text { Selective } & \text { Selective } & \text { Selective } & \text { Automated } & \text { Broad-band } & \text { Narrow-band } & \text { Hypo- } \\ \text { Low-e } & \text { Low-e } & \text { Low-e } & \text { Venetian } & \text { Electro- } & \text { Electro- } & \text { thetical } \\ \text { No Shades } & \text { No Shades } & \text { Shades } & \text { Blind } & \text { chromic } & \text { chromic } & \text { Optimum } \\ \text { No Daylight } & \text { Daylight } & \text { Daylight } & \text { Daylight } & \text { Daylight } & \text { Daylight } & \text { Daylight }\end{array}$

\begin{tabular}{|c|c|c|c|c|c|c|c|c|}
\hline \multicolumn{9}{|c|}{ Annual Electricity Use (kWh) } \\
\hline Zone & WWR & & & & & & & \\
\hline \multirow[t]{5}{*}{ North } & 0.00 & 12,602 & 12,592 & 12,604 & & 12,593 & 12,591 & 6,481 \\
\hline & 0.15 & 12,803 & 10,081 & 10,091 & & 9,961 & 9,559 & 6,481 \\
\hline & 0.30 & 12,991 & 8,365 & 8,367 & & 8,404 & 7,815 & 6,481 \\
\hline & 0.50 & 13,236 & 8,002 & 8,002 & 8,277 & 7,869 & 7,252 & 6,481 \\
\hline & 0.70 & 13,511 & 8,090 & 8,088 & & 7,724 & 7,113 & 6,481 \\
\hline \multirow[t]{5}{*}{ East } & 0.00 & 12,834 & 12,817 & 12,824 & & 12,819 & 12,814 & 6,471 \\
\hline & 0.15 & 13,491 & 10,025 & 10,093 & & 10,041 & 9,392 & 6,471 \\
\hline & 0.30 & 15,372 & 10,333 & 9,051 & & 9,148 & 8,141 & 6,471 \\
\hline & 0.50 & 17,854 & 12,240 & 9,639 & 9,996 & 9,366 & 7,528 & 6,471 \\
\hline & 0.70 & 20,333 & 14,559 & 10,888 & & 9,889 & 7,321 & 6,471 \\
\hline \multirow[t]{5}{*}{ South } & 0.00 & 12,913 & 12,889 & 12,902 & & 12,894 & 12,886 & 6,511 \\
\hline & 0.15 & 14,119 & 9,414 & 9,565 & & 9,619 & 8,795 & 6,511 \\
\hline & 0.30 & 16,703 & 11,243 & 9,057 & & 9,531 & 8,033 & 6,511 \\
\hline & 0.50 & 20,043 & 14,281 & 10,577 & 10,615 & 10,057 & 7,590 & 6,511 \\
\hline & 0.70 & 23,316 & 17,433 & 12,323 & & 10,698 & 7,373 & 6,511 \\
\hline \multirow[t]{5}{*}{ West } & 0.00 & 12,823 & 12,804 & 12,816 & & 12,808 & 12,801 & 6,410 \\
\hline & 0.15 & 13,663 & 9,868 & 10,007 & & 9,997 & 9,203 & 6,410 \\
\hline & 0.30 & 15,775 & 10,426 & 8,944 & & 9,126 & 7,976 & 6,410 \\
\hline & 0.50 & 18,571 & 12,760 & 9,849 & 10,720 & 9,856 & 7,519 & 6,410 \\
\hline & 0.70 & 21,435 & 15,494 & 11,407 & & 10,517 & 7,354 & 6,410 \\
\hline
\end{tabular}

Peak Demand (W), WWR $=0.50$

$\begin{array}{lrrrrrr}\text { North } & 6,707 & 6,102 & 6,098 & 5,670 & 6,227 & 5,663 \\ \text { East } & 10,051 & 9,411 & 7,587 & 7,455 & 7,329 & 5,923 \\ \text { South } & 10,555 & 9,868 & 7,744 & 7,523 & 7,585 & 6,005 \\ \text { West } & 10,116 & 9,443 & 5,854 & 7,859 & 7,699 & 6,060\end{array}$



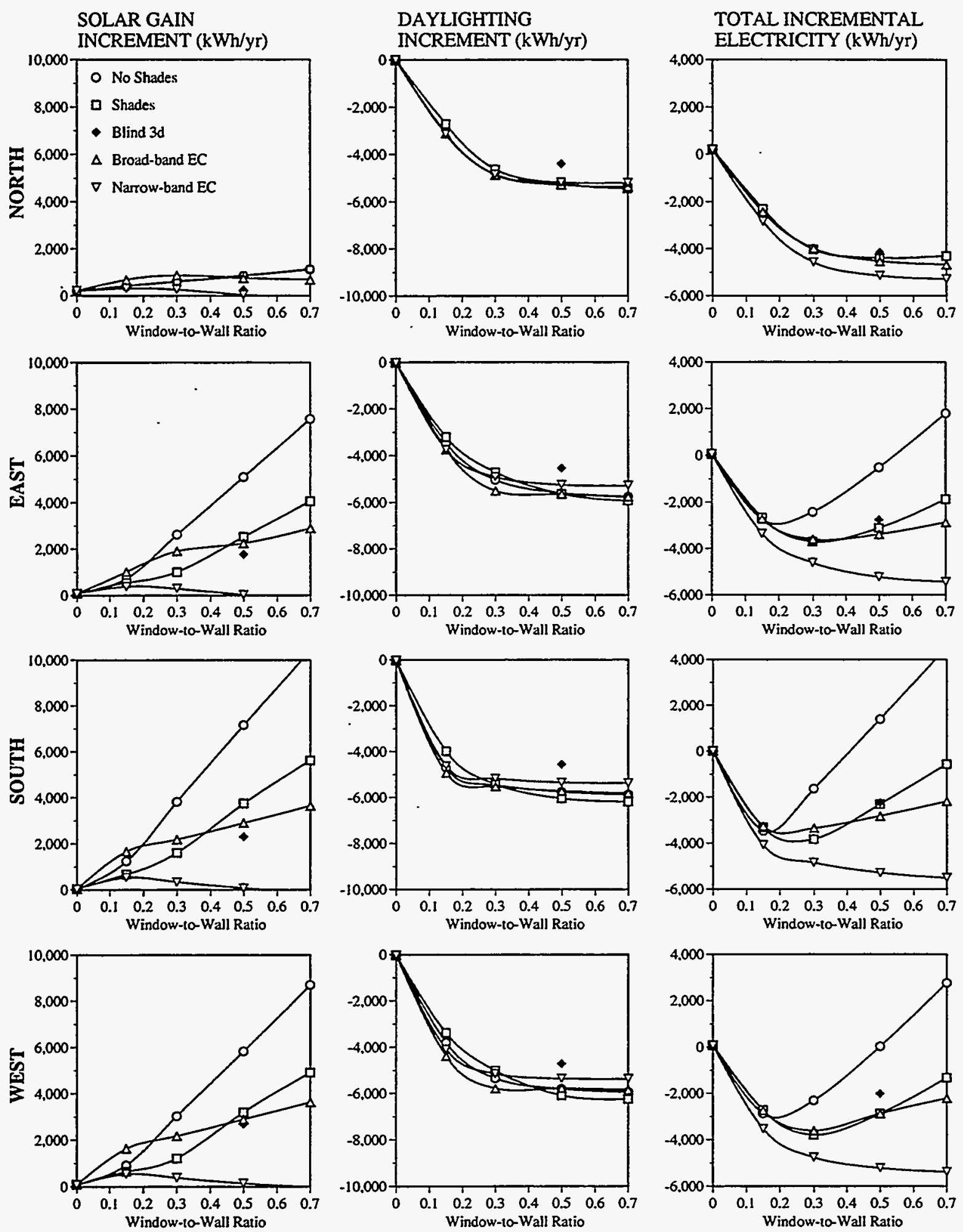

Figure 4. Incremental electricity consumption for a prototypical commercial office building zone in Los Angeles. The data show the performance of selective low-e IG glazing with and without shade, and an automated venetian blind with control strategy $3 d$, and the narrow-band and broad-band electrochromics. All systems use continuous daylighting controls at a design lighting level of $50 f c(538 \mathrm{lux})$ and a lighting power density of $1.5 \mathrm{~W} / \mathrm{ft}^{2}\left(16.1 \mathrm{~W} / \mathrm{m}^{2}\right)$. A perimeter zone has ten $10 \mathrm{ft}(3.05 \mathrm{~m})$ wide by $15 \mathrm{ft}(4.57 \mathrm{~m})$ deep offices. 
control strategy design, e.g., through the use of predictive control algorithms, or by altering the solar-optical properties of the system. For example, if the venetian blind can achieve a similar bound on SC as the narrow-band electrochromic and maintain or raise its daylighting performance, this system performance may approach that of the narrow-band electrochromic. The daylighting performance of the venetian blind system can be improved if continuous tilt angles are used instead of discrete $15^{\circ}$ increments, if the blind is fully retracted during periods of low daylight availability, or if the shape of the louver or the color of its surface is designed to increase daylight admission. Increased specularity of the louver surface can also be used to reflect incoming solar radiation and reduce solar heat gains.

\section{Multiple Control Strategies/Single Criterion}

In the above discussion, each simple control strategy was evaluated on the basis of its ability to satisfy one criterion: minimize energy use. Calculations for energy use were based on using the same control strategy throughout the year. The performance of these simple control strategies may be improved yet still remain outside the domain of predictive control, if the objective of the control strategy is changed on a month-to-month basis in response to changes in daylight availability, heating/cooling seasons, or timeof-use utility rate schedules. An investigation into hourly control algorithms was beyond the scope of this study.

This concept of combining multiple control strategies is illustrated for the automated venetian blind system (Figure 5a). Strategies 2 and $3 a$ are used to minimize monthly electricity consumption in the south-facing perimeter zone. Strategy 2 maximizes workplane illuminance at $12.86 \mathrm{ft}$ (3.92 $\mathrm{m})$, reaching $70-80 \%$ of the optimum daylighting increment for all months of the year but with large solar heat gains, particularly during the winter months. Strategy $3 a$, maximizes workplane illuminance at $6.43 \mathrm{ft}(1.96 \mathrm{~m})$ without exceeding the design illuminance at the same point. This cap on workplane illuminance effectively reduces daylight saturation to $20-30 \%$ of the optimum daylighting increment but it also produces an effective strategy in controlling solar heat gains. In this example, if control strategy $3 a$ is used from October through February and strategy 2 is used from March through September,
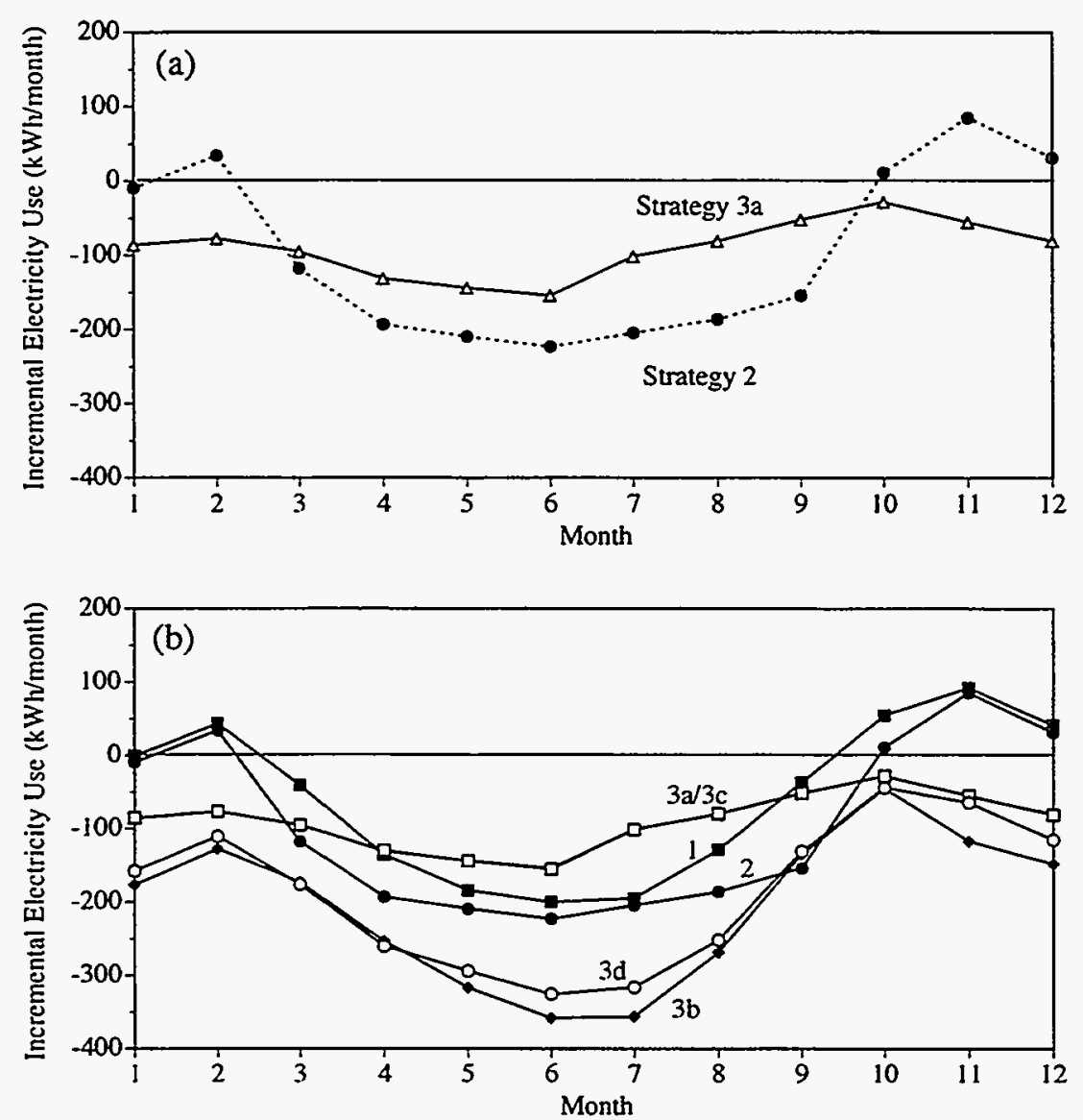

Figure 5a (top). Incremental electricity consumption for an automated venetian blind system using two control strategies to minimize electricity consumption ( $k W h / m o n t h$ ) in the south-facing perimeter zone. Control strategy 2 is designed to maximize workplane illuminance at $12.86 \mathrm{ft}(3.92 \mathrm{~m})$. Control strategy $3 a$ is designed to maximize workplane illuminance at $6.43 \mathrm{ft}$ $(1.96 \mathrm{~m})$ without exceeding the design illuminance at $6.43 \mathrm{ft}$. Data are given for a prototypical commercial office building zone $(1500$ $\left.f^{2}\right)$ with $W W R=0.50$ in Los Angeles.

Figure $5 b$ (bottom). Incremental electricity consumption for an automated venetian blind system using six control strategies in the southfacing perimeter zone. 
annual electricity use is lowered. Annual incremental energy use is reduced from $-1080 \mathrm{kWh} / \mathrm{yr}$ (strategy $3 \mathrm{a}$ ) or $-1131 \mathrm{kWh} / \mathrm{yr}$ (strategy 2) with the use of a single control strategy to $-1611 \mathrm{kWh} / \mathrm{yr}$ with the use of multiple control strategies.

Between all the automated venetian blind control strategies investigated, however, using multiple control strategies does not provide energy savings over the use of the best of the single control strategies (Figure 5b). Strategies $3 \mathrm{~b}$, maximize workplane illuminance at $6.43 \mathrm{ft}(1.96 \mathrm{~m})$, and $3 \mathrm{~d}$, optimize workplane illuminance at $12.86 \mathrm{ft}$ ( 3.92 $\mathrm{m})$, provide the most daylight for the least amount of solar gains consistently throughout all months of the year. This can be determined by-visually inspecting for energy use lines that cross over other energy use lines when one strategy performs better than another. For all orientations, most of the energy use lines are parallel or do not vary significantly between strategies. Only for the poorer performing strategies, as in the example from Figure 5a, does this crossover occur.

Although there were no gains in energy performance with the use of multiple control strategies in this example, there may be benefits in other situations. The automated venetian blind control strategies used above indirectly minimize energy consumption by using six different modes of operation to optimize the same parameter. workplane illuminance. Multiple control strategies based on lighting and solar loads may yield higher energy savings. Multiple control strategies implemented on an hourly versus monthly basis may also yield higher energy savings. Future work will investigate these options further.

\section{Multiple Control Strategies/Multiple Criteria}

In the above examples, other equally important performance criteria, such as minimizing peak demand, are satisfied only as indirect by-products of meeting energy performance goals. Control strategies should be designed to meet multiple performance criteria; i.e., minimize peak demand, operating cost, visual and thermal discomfort. Resolving multiple, possibly conflicting criteria, however, can lead to an involved and cumbersome process of rulemaking or determining weighting factors, etc. that will in most cases, result in only some of the criteria being partially satisfied. The resolution of multiple criteria will affect the realized energy performance of dynamic envelope and lighting systems, and should therefore be investigated with as much care as predictive control algorithms.
The inherent difficulty of resolving multiple criteria is illustrated with an example in Figure 6. Here, the venetian blind system employs three control strategies to meet two performance criteria: minimize electricity consumption and peak demand. For the west-facing zone, no conflict arises between satisfying both criteria on a monthly basis. Strategy 3d, optimize workplane illuminance at $12.86 \mathrm{ft}$ $(3.92 \mathrm{~m})$, satisfies both criteria from November through March, and strategy 2, maximize workplane illuminance.at $12.86 \mathrm{ft}$, satisfies both during the remainder of the year. For the south-facing zone, however, three conflicts arise between strategies 2 and 3d in April, August, and October (Table 3).

From the perspective of the building owner, the important objective is to minimize operating cost by lowering electricity consumption and peak demand. In this example, the lower monthly electricity consumption may result in lower cost during the summer since there is a small $5 \%$ difference in peak demand between strategies 2 and $3 \mathrm{~d}$. From the viewpoint of the utility, however, these small differences in summer peak demand between strategies can add up over many buildings (or for a large building) to be a significant contribution to peak generating capacity requirements. The difficulty of resolving conflicts between 3

TABLE 3
Monthly Electricity and Peak Demand for a
Prototypical South Facing Perimeter
Zone $\left(1500 \mathrm{ft}^{2}\right)$ in Los Angeles

$\begin{array}{clll}\text { Month } & \begin{array}{l}\text { Control } \\ \text { Strategy }\end{array} & \begin{array}{l}\text { Peak } \\ \text { Demand } \\ (\mathrm{kW})\end{array} & \begin{array}{l}\text { Electricity } \\ \text { Consumption } \\ \text { (kWh/mon) }\end{array} \\ \text { April } & 1 & 4.76 & 936.1 \\ & 2 & 4.45< & 878.8 \\ & 3 \mathrm{~d} & 4.58 & 811.8< \\ \text { August } & 1 & 5.39 & 1120.0 \\ & 2 & 5.07< & 1062.9 \\ & 3 \mathrm{~d} & 5.31 & 997.4< \\ \text { October } & 1 & 5.79 & 1150.3 \\ & 2 & 5.34< & 1107.0 \\ & & & \\ & 3 \mathrm{~d} & 6.03 & 1051.7<\end{array}$

Control Strategy 1: Maximize View Control Strategy 2: Maximize Workplane Illuminance Control Strategy 3d: Optimize Workplane Illuminance 

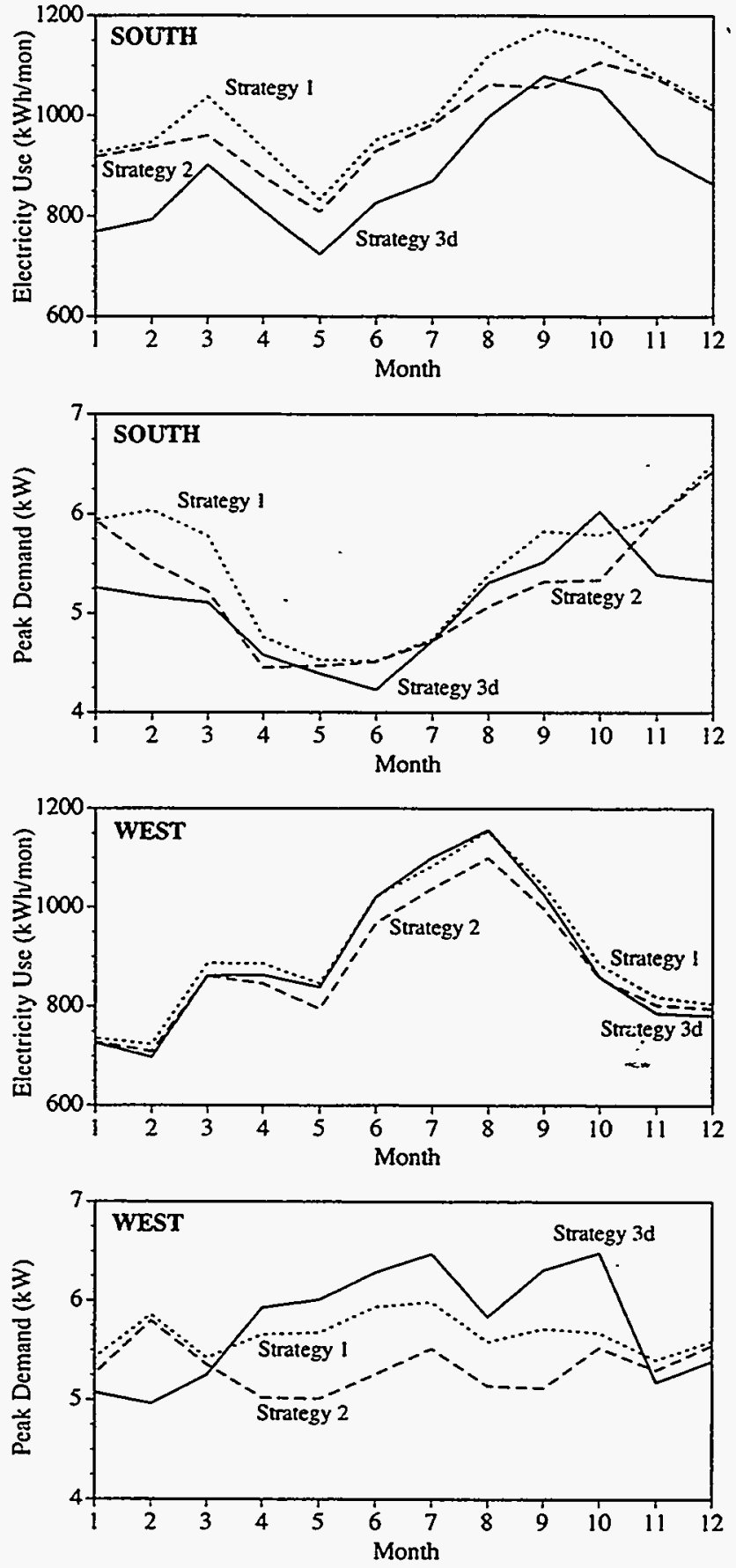

Figure 6. Peak demand $(k W)$ and total electricity consumption ( $k W h / m o n t h$ ) for south and west facing perimeter zones with the automated venetian blind system and control strategies I (maximize view), 2 (maximize workplane illuminance), and $3 d$ (optimize workplane illuminance) with daylighting controls. All control strategies block direct sun. Data are given for a prototypical commercial office building zone $\left(1500 \mathrm{ft}^{2}\left(139.35 \mathrm{~m}^{2}\right)\right)$ with WWR $=0.50$ in Los Angeles. performance criteria is due principally to the different "value" perceived by the various end-users and the incomparability between various criteria; i.e., peak demand, which has economic value to both the owner and utility, and glare, which has a major effect on occupants but no direct effect on utilities. Additional sophistication in control strategy design is warranted. If well designed and implemented in software, a multi-criteria control strategy with operational flexibility may be ultimately invisible to the occupant and require no additional effort and cost.

\section{CONCLUSIONS}

The energy performance of simple control strategies based on instantaneous measured data was compared to the performance of an optimum hypothetical dynamic envelope and lighting system in order to determine the incremental benefit of using more complex, predictive control algorithms. The energy performance of the simple control strategies was related to the solar-optical properties of the dynamic envelope and lighting system, window orientation, and window area for a prototypical commercial building in Los Angeles. Performance analysis for this weather profile suggests that:

1. Energy and peak demand savings are highly dependent on the control strategy of the dynamic envelope and lighting system. Simple control strategies that decrease lighting energy and cooling due to lighting energy by admitting sufficient daylight, and that decrease cooling due to solar gains by limiting excessive daylight will achieve the best energy performance.

2. The success of the control strategy is highly dependent on the range of optical and thermal characteristics of the dynamic envelope system: for the same control strategy (e.g., meet design workplane illuminance), the narrowband electrochromic was able to achieve substantially betterperformance than the broad-band electrochromic for all orientations and variations in glazing area because it had a lower $\mathrm{SC}$ range.

3. The hypothetical narrow-band electrochromic was able to achieve near-optimum energy performance due to its selective solar-optical range. For this type of dynamic envelope and lighting system, predictive control algorithms may produce small energy benefit for the complexity and possible cost required for its implementation. For all other dynamic envelope and lighting systems investi- 
gated in this study, however, predictive control algorithms may result in significantly larger energy savings, and should therefore be investigated.

4. If a dynamic envelope and lighting system can improve its control of solar-optical properties over a wider range to more closely mimic that of the narrow-band electrochromic, predictive control algorithms may result in smaller energy reductions. For example, the automated venetian blind system may be able to improve its "solaroptical range" by altering its surface reflectance, by retracting the blinds to a full up position during periods of low daylight availability, or by using continuous tilt angles rather than $15^{\circ}$ discrete tilt angles as modeled in this study.

5. As glazing area increases (WWR $>0.30$ ), the energysavings potential of predictive control algorithms increases for dynamic systems such as the broad-band electrochromic system. Since the automated venetian blind data are given for a single glazing area ( $W W R=0.50$ ), no conclusions can be made about the relationship of the automated venetian blind system to glazing area.

6. For the north orientation, simple control strategies will suffice, since the difference in energy performance between simple versus predictive control algorithms is relatively small. For all other orientations, the use of simple or predictive control algorithms will be dependent on the other factors mentioned above.

7. Using multiple, simple control strategies on a seasonal or month-by-month basis will not provide substantially more energy savings for the subset of automated venetian blind control strategies investigated in this study. This option was proposed as a means of combining simple strategies into more "complex"strategies, while remaining outside the domain of predictive control algorithms. Further investigation is warranted to explore multiple control strategy schemes that are designed to optimize the reduction of solar heat gains, or to respond to heating/cooling seasons or utility real-time pricing schedules.

8. Both simple and predictive control algorithms must be designed to meet multiple performance criteria: electricity consumption, peak demand, cost, and occupant preferences. The operation of a dynamic system must accommodate occupant preferences even if this can potentially reduce realized energy savings: systems that do not allow override, or do not accommodate the physiological (e.g., thermal and visual comfort) and psychological (e.g., view or contact with outdoors) criteria of humans are typically sabotaged by the occupant or are not specified by the design engineer or architect. To select the state of the dynamic device, the control strategy must incorporate a system to resolve conflicts between computational directives and human subjective preferences. If implemented in software, more complex control strategies should not result in increased cost.

\section{ACKNOWLEDGMENTS}

The authors are indebted to their LBL colleagues, Robert Sullivan, Konstantinos Papamichael, Liliana Beltrán, Fred Winkelmann, and W. Fred Buhl for their assistance in experimental and simulation modeling. In addition, thanks are due to student assistants, Paul Fritz and Jessica Rothschild, for their assistance in experimental set-up for the venetian blind prototype. This research was funded by the California Institute for Energy Efficiency (CIEE), a research unit of the University of California. Publication of research results does not imply CIEE endorsement of or agreement with these findings, nor that of any CIEE sponsor. Additional related support was provided by the Assistant Secretary for Energy Efficiency and Renewable Energy, Office of Building Technologies, Building Systems and Materials Division of the U.S. Department of Energy under Contract No. DE-AC03-76SF00098.

\section{REFERENCES}

Athienitis, A.K., M. Stylianou, and J. Shou. 1990. A methodology for building thermal dynamics studies and control applications. ASHRAE Transactions 96 (2).

Hartman, T.B. 1988. Dynamic control: Fundamentals and considerations. ASHRAE Transactions 94 (1): 599-609.

Inoue, T., T. Kawase, T. Ibamoto, S. Takakusa, and Y. Matsuo. 1988. The development of an optimal control system for window shading devices based on investigations in office buildings. ASHRAE Transactions 94 (2): 1034-1049.

Johnson, R. et al. 1983. Building envelope thermal and daylighting analysis in support of recommendations to upgrade ASHRAE/IES Standard 90. LBL Report 16770 (September), Lawrence Berkeley Laboratory, Berkeley, CA. 
Kelly, G.E. 1988. Control system simulation in North America. Energy and Buildings 10: 193-202.

Kreider, J.F. and X.A. Wang. 1991. Artificial neural networks demonstration for automated generation of energy use predictors for commercial buildings. ASHRAE Transactions 97 (2).

Lampert, C.M. and Y.P. Ma. 1993. Fenestration 2000 Phase 1II: Advanced glazing materials study. Oxfordshire: U.K. Department of Energy, ETSU, B 156 Harwell Laboratory, United Kingdom OXI10RA:

Papamichael, K., F. Rubinstein, S. Selkowitz, and G. Ward. 1986. The integration of operable shading systems and electric lighting controls. Proceedings of the 1986 International Daylighting Conference, November 5-7, Long Beach, CA.

Papamichael, K. and L. Beltrán. 1993. Simulating the daylight performance of fenestration systems and spaces of arbitrary complexity: The IDC method. Proceedings of the Third International Conference of the International Building Performance Simulation Association, Building Simulation '93, August 16-18, 1993, Adelaide, Australia, pp. 509-515. LBL Report 33945, Lawrence Berkeley Laboratory, Berkeley, CA.

Reilly, S., D. Arasteh, and S. Selkowitz. 1991. Thermal and optical analysis of switchable window glazings. Solar Energy Materials 22: 1-14. LBL Report 29629, Lawrence Berkeley Laboratory, Berkeley, CA.

Rheault, S. and E. Bilgen. 1987. Heat transfer optimization of an automated venetian blind window system. ASES 12th National Passive Solar Conference, Portland, OR, pp. 122-128.

Rheault, S. and E. Bilgen. 1990. Experimental study of full-size automated venetian blind windows. Solar Energy 44 (3): 157-160.

Rubinstein, F., D. DiBartolomeo, A. Hamilton, E.S. Lee, and S. Selkowitz 1994. Implementation of a dynamic envelope and lighting system. Working information (January 14, 1994) for the multiyear project "Envelope and Lighting Technology to Reduce Electric Demand Phase II," California Institute for Energy Efficiency (CIEE), Lawrence Berekeley Laboratory.
Simulation Research Group. 1982. DOE-2 Engineer's Manual, Version 2.1A (November 1982). LBL Report 11353, Lawrence Berkeley Laboratory, Berkeley, CA.

Simulation Research Group. 1989. DOE-2 Supplement, Version2.ID, LBL Report 8706, Rev.5Suppl.,Lawrence Berkeley Laboratory, Berkeley, CA.

Stoecker, W.F. and P.A. Stoecker. 1989. Microcomputer control of thermal and mechanical systems. New York: Van Nostrand Reinhold.

Sullivan, R., E. S. Lee, and S. Selkowitz. 1992. A method of optimizing solar control and daylighting performance in commercial office buildings. Proceedings of the ASHRAEIDOEIBTECC Conference on the Thermal Performance of the Exterior Envelopes of Buildings $V$, Clearwater Beach, FL, December 7-10, 1992. LBL Report 32931, Lawrence Berkeley Laboratory, Berkeley, CA.

Warner, J.L., M. S. Reilly, S.E. Selkowitz, D. K. Arasteh, and G. D. Ander. 1992. Utility and economic benefits of electrochromic smart windows. Proceedings of the ACEEE 1992 Summer Study on Energy Efficiency, August 30-September 5, 1992, Pacific Grove, CA. LBL Report 32638, Lawrence Berkeley Laboratory, Berkeley, CA.

\section{APPENDIXES}

\section{A. Building Simulation Model Prototype}

A five-zone prototypical office module developed and used by the Lawrence Berkeley Laboratory over the course of ten years was used for this analysis (Johnson et al. 1983). To isolate the energy effects of interest, interior surfaces were modeled as adiabatic surfaces (no heat transfer). The effect of the thermal capacitance of the building was not studied. The building construction materials were designed to model light-weight construction. The exterior walls were modeled as no-mass quick walls with $U$-value $=0.091 \mathrm{Btu} / \mathrm{h} \cdot \mathrm{ft}^{2} \cdot{ }^{\circ} \mathrm{F}\left(0.52 \mathrm{~W} / \mathrm{m}^{2} \cdot \mathrm{K}\right)$. The floors were modeled as adiabatic surfaces consisting of carpeting with a fibrous pad (U-value $=0.481 \mathrm{Btu} / \mathrm{h} \cdot \mathrm{ft}^{2} \cdot{ }^{\circ} \mathrm{F}\left(2.73 \mathrm{~W} / \mathrm{m}^{2} \cdot \mathrm{K}\right)$ ) over a $0.33 \mathrm{ft}(0.10 \mathrm{~m})$ thick, $80 \mathrm{lb} / \mathrm{ft}^{3}\left(5 \mathrm{~kg} / \mathrm{m}^{3}\right)$ concrete slab. The ceiling were modeled as adiabatic surfaces consisting of $0.0417 \mathrm{ft}(0.013 \mathrm{~m})$ acoustical tile with the concrete floor slab above it. The interior partitions consisted of $0.0521 \mathrm{ft}(0.016 \mathrm{~m})$ gypsum board over stud walls. 
To isolate zone loads from building system interactions, a separate single-zone constant-volume system was assigned to each zone. A constant cooling system coefficient of performance (3.0) converted the system loads to energy use. Hourly data therefore reflects a fixed COP for part load performance and variations in exterior temperature and humidity conditions. Proportional thermostat cooling setpoints for weekdays were $72^{\circ} \mathrm{F}\left(22.2^{\circ} \mathrm{C}\right)$ for $7: 00-19: 00$ and $90^{\circ} \mathrm{F}\left(32.2^{\circ} \mathrm{C}\right)$ for $19: 00-7: 00$, and $90^{\circ} \mathrm{F}$ for all hours of the weekends and holidays. The design cooling temperture was set at $78^{\circ} \mathrm{F}\left(25.6^{\circ} \mathrm{C}\right)$. A more detailed descriptions of the load schedules and HVAC characteristics can be found in Johnson et al. (1983).

There are three modeling differences between the prototype (A) used to analyze the conventional glazings and electrochromics, and the prototype (B) used to analyze the venetian blinds: ceiling height ( $8.5 \mathrm{ft}$ versus $9.0 \mathrm{ft}(2.59 \mathrm{~m}$

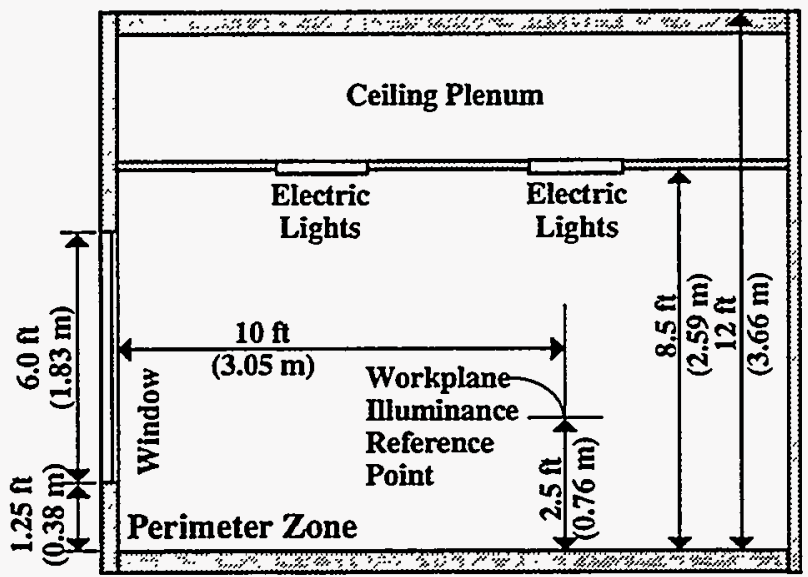

Conventional and Electrochromic Prototype (WWR=0.50)

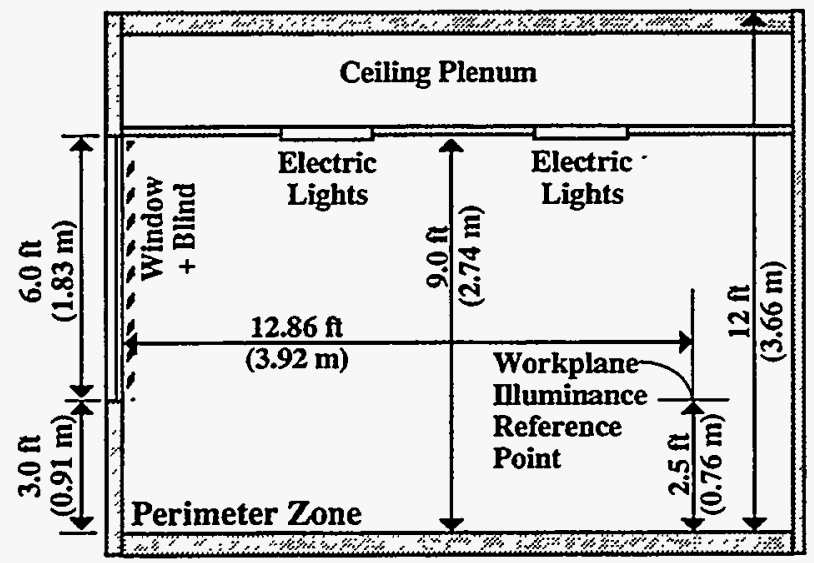

Automated Venetian Blind Prototype (WWR=0.50)

Figure 7. DOE-2 Prototype Building Section versus $2.74 \mathrm{~m}$ )), light reference point locations (10 ft versus $12.86 \mathrm{ft}(3.05 \mathrm{~m}$ versus $3.92 \mathrm{~m})$ ), and placement of the window in the window wall (Figure 7). These modeling differences created an insignificant difference in annual energy use: a maximum of $1.34 \%$ difference between prototypes $\mathrm{A}$ and $\mathrm{B}$ for a full range of glazing types and window areas (0-70\%).

\section{B. Daylight and Thermal Modeling of the Venetian Blinds}

To accurately model the daylight performance of the venetian blind we developed a new method that combines experimental measurements in scale models and mathematical routines to produce daylight factors. This experimentally-based method has the advantage of accurately modeling the bi-directional reflectance and/or transmittance of any material, including specular surfaces, without the reliance on numerical prediction models.

A $10 \mathrm{ft}(3.05 \mathrm{~m})$ wide, $15 \mathrm{ft}(4.57 \mathrm{~m})$ deep, and $9 \mathrm{ft}(2.74$ $\mathrm{m})$ high interior space was modeled at $1 \mathrm{ft}(0.305 \mathrm{~m})$ realscale to 1.175 inch $(0.0298 \mathrm{~m})$ model scale to meet the constraints of the experimental facility. Surface reflectances of $43.5 \%$ walls, $21.0 \%$ floor, and $76.3 \%$ ceiling were used. The window wall has a $3 \mathrm{ft}(0.914 \mathrm{~m})$ sill height, window opening of $6 \mathrm{ft}(1.83 \mathrm{~m})$ high by $10 \mathrm{ft}(3.05 \mathrm{~m})$ wide, and a head height of $9 \mathrm{ft}(2.74 \mathrm{~m})$. An interior semi-matte white venetian blind was used with a $3 \mathrm{~mm}$ conventional selective low-e IG glazing (Tv=0.66); the Tv of the DOE-2 simulation model and scale model for optical measurements were closely matched. For each blind tilt angle, we constructed a separate window facade with 14 to 15 fixed louvers 0.5 inch $(0.0127 \mathrm{~m})$ wide $(5.1 \mathrm{inch}(0.1295 \mathrm{~m})$ realscale), positioned 0.67 inches apart $(0.017 \mathrm{~m})(6.8$ inches $(0.173 \mathrm{~m})$ real-scale, $L / D=0.75)$ for the full height of the window. Thirty cosine corrected, color corrected photometers were placed within the model: three rows of six equally spaced from side to side and front to back to measure workplane illuminance at $2.5 \mathrm{ft}(0.762 \mathrm{~m})$ realscale, with additional sensors to measure the interior surface luminance levels.

Photometric measurements were repeated for each of eleven blind tilt angles from $-75^{\circ}$ to $+75^{\circ}$ at $15^{\circ}$ increments using the LBL Scanning Radiometer facility. Measurements were taken for discrete light source positions at regular intervals over the hemisphere seen by the window aperture. These measurements were then mathematically integrated over the CIE sky and ground plane (reflectance $=0.2$ ) 
luminance distribution to produce sun, clear sky and overcast sky daylight factors. At the fully closed position (tilt angle $= \pm 90^{\circ}$ ), the workplane illuminance levels were assumed to be zero. More information concerning the mathematical algorithms is given in Papamichael and Beltrán (1993). These factors were then used in a modified version of the DOE-2 building energy simulation program to determine workplane illuminance on an hourly basis.

There are currently no known models that characterize the thermal performance of venetian blinds as a function of solar azimuth, solar altitude, sky condition, and blind tilt angle that can be readily incorporated into the DOE-2 building energy simulation program. We have used shading coefficient (SC) data derived for a louver system hermetically sealed between two glass panes (Rheault and Bilgen 1987). Data for the shading coefficient versus louver tilt angle were given for average winter and summer solar positions. Solar azimuthal positions that are not parallel to the surface normal of the window were not accounted for. A comprehensive and more accurate model of the relationship between solar heat gain and blind and glazing properties as a function of sun and sky conditions for all window orientations will be needed for future work. 